\title{
MODELING THE SPATIAL AND TEMPORAL DIMENSIONS OF RECREATIONAL ACTIVITY PARTICIPATION WITH A FOCUS ON PHYSICAL ACTIVITIES
}

\author{
Ipek N. Sener \\ Texas Transportation Institute \\ Texas A\&M University System \\ 1106 Clayton Lane, Suite 300E, Austin, TX, 78723 \\ Phone: (512) 467-0952, Fax: (512) 467-8971 \\ Email: i-sener@ttimail.tamu.edu
}

\author{
Chandra R. Bhat* \\ The University of Texas at Austin \\ Department of Civil, Architectural \& Environmental Engineering \\ 1 University Station, C1761, Austin, TX 78712-0278 \\ Phone: (512) 471-4535, Fax: (512) 475-8744 \\ Email: bhat@mail.utexas.edu
}

*corresponding author 


\begin{abstract}
This study presents a unified framework to understand the weekday recreational activity participation time-use of adults, with an emphasis on the time expended in physically active recreation pursuits by location and by time-of-day. Such an analysis is important for a better understanding of how individuals incorporate physical activity into their daily activities on a typical weekday, and can inform the development of effective policy interventions to facilitate physical activity. Furthermore, such a study of participation and time use in recreational activity episodes contributes to activity-based travel demand modeling, since recreational activity participation comprises a substantial share of individuals' total non-work activity participation. The methodology employed here is the multiple discrete continuous extreme value (MDCEV) model, which provides a unified framework to explicitly and endogenously examine time use by type, location, and timing. The data for the empirical analysis is drawn from the 2000 Bay Area Travel Survey (BATS), supplemented with other secondary sources that provide information on physical environment variables. To our knowledge, this is the first study to jointly address the issues of 'where', 'when' and 'how much' individuals choose to participate in 'what type of (recreational) activity'.
\end{abstract}

Keywords: Adult's recreational activity, physical activity, activity time use, urban form, activity location, activity timing, multiple discrete continuous models. 


\section{INTRODUCTION}

\subsection{Background}

Over the last two decades, several research studies have examined the factors that affect obesity levels. Among other things, these studies have found clear evidence that obesity is strongly correlated with physical inactivity. For instance, Struber (2004) indicated that the "prevalence of obesity is more closely related to decreases in energy expenditure (perhaps creating a chronic energy imbalance), than to increases in energy intake, strongly implicating physical inactivity in the etiology of obesity” (see also Westerterp, 2003). In addition to influencing obesity, physical inactivity is a primary risk factor for the onset of several diseases such as coronary heart disease and colon cancer, and it is an important contributing factor to mental health diseases such as depression and anxiety (see Struber, 2004 and USDHHS, 2008). On the other hand, physical activity increases cardiovascular fitness, enhances agility and strength, and improves mental health (CDC, 2006 and USDHHS, 2008).

Despite the adverse impacts of physical inactivity (and the health benefits of physical activity), sedentary (or physically inactive) lifestyles are quite prevalent among adults in the U.S. In particular, according to the 2007 Behavioral Risk Factor Surveillance System (BRFSS) survey, almost half of U.S. adults do not engage in recommended levels of physical activity, and almost one-third of U.S. adults are physically inactive. ${ }^{1}$ Similarly, the 2007 Youth Risk Behavior Surveillance survey indicates that about $65.3 \%$ of high school students do not meet current physical activity guidelines. ${ }^{2}$ It is not surprising, therefore, that there is now a reasonably large body of literature on examining the factors affecting the physical activity behavior of individuals, with the end-objective of using these insights to design intervention strategies to promote physically active lifestyles. However, most of these earlier studies focus on examining attributes influencing the level and/or intensity of physical activity participation, such as whether an individual participates in physical activity and/or the amount of time expended in physical activity (for example, see Cohen et al., 2007, Salmon et al., 2007, and Srinivasan and Bhat, 2008). There has been relatively little attention on the temporal and spatial context of the

\footnotetext{
${ }^{1}$ The current adult physical activity guidelines call for at least 150 minutes a week of moderate-level physical activity (such as brisk walking, bicycling, water aerobics) or 75 minutes a week of vigorous-level physical activity (such as jogging, running, mountain climbing, bicycling uphill) (USDHHS, 2008).

${ }^{2}$ The current guidelines call for children and adolescents to participate in at least 60 minutes of physical activity every day, and this activity should be at a vigorous level at least 3 days a week (USDHHS, 2008).
} 
physical activity participations, that is, on the "when" and "where" of physical activity participation. On the other hand, an understanding of the temporal and spatial contexts of physical activity participation can provide important insights to design customized physically active lifestyle promotion strategies at different locations (such as in-home versus a gym) and times of the day to target specific demographic groups.

Of course, an examination of recreational activity participation in general is also important from a transportation perspective. Out-of-home $(\mathrm{OH})$ recreational activity episode participation comprises a substantial share of total $\mathrm{OH}$ non-work activity episode participation on a typical weekday. For instance, Lockwood et al. (2005) examined data from San Francisco, and observed that about $20 \%$ of all non-work activity episodes during a typical workday are associated with physically inactive or physically active recreation. The share contributed by $\mathrm{OH}$ recreation episodes to total $\mathrm{OH}$ non-work episodes was only next to the share contributed by serve passenger episodes. Further, Lockwood et al. also found that, among all non-work episodes, recreation episodes entailed the longest travel distances, and generated the highest person miles of travel and vehicle miles of travel. In addition to the sheer volume of participation and travel mileage attributable to $\mathrm{OH}$ recreational activity participation, there is quite substantial joint activity participation and joint travel associated with $\mathrm{OH}$ recreational activity, especially between children and adults within a household (see, for instance, Gliebe and Koppelman, 2002 and Kato and Matsumoto, 2009). Thus, from an activity-based travel demand perspective, a study of participation and time-use in $\mathrm{OH}$ recreational activities, as well as the spatial and temporal dimensions of these participations, is important. In doing so, one needs to distinguish between $\mathrm{OH}$ physically active and physically inactive participations, since the temporal and spatial contexts of these two types of participations (such as time of day, spatial location, travel, and duration of time investment) tend to be very different (Lockwood et al., 2005). In addition, out-of-home recreation participations also need to be distinguished from in-home participations, since the former entail travel while the latter do not. Besides, there may be substitution between in-home, $\mathrm{OH}$ physically inactive, and $\mathrm{OH}$ physically active recreational participations (Bhat and Gossen, 2004). Finally, transportation researchers are increasingly being drawn into the study of recreational activity participation and time-use because of the potential association between built environment attributes and levels of physical activity participation (for example, Handy et al., 
2005, Moudon et al., 2005, Cao et al., 2006, Copperman and Bhat, 2007, Sener et al., 2008, and Devlin et al., 2009).

\subsection{The Current Paper}

In the current paper, we use an activity diary survey to model adults' overall recreational activity participation on weekdays, with an emphasis on the time expended in physically active recreation by location and by time-of-day. In terms of location, we have no way to differentiate between physically inactive and physically active recreational pursuits in-home, because, as discussed later in the data section, the only way in the data to identify if a recreational episode is physically active or not is based on the location type classification of the out-of-home activity episode (such as bowling alley, gymnasium, shopping mall, or movie theatre). Thus, we use a composite in-home recreation category. However, for out-of-home recreation pursuits, we are able to distinguish between physically inactive and physically active episodes. In the current analysis, we retain out-of-home physically inactive recreation as a single category, but categorize the time invested in out-of-home physically active recreation in one of three location categories: (1) Fitness center/health club/gymnasiums (or simply "club" for brevity), (2) In and around residential neighborhood (such as walking/biking/running around one's residence without any specific destination for activity participation; we will refer to this location as "neighborhood"), and (3) Park/outdoor recreational area (“outdoors” for brevity). Further, the time invested in outof-home physically active recreation is categorized temporally in one of the following four time periods of the weekday: (1) AM peak (6:01 AM - 9 AM), (2) Midday (9:01 AM - 4 PM), (3) PM peak (4:01 PM - 7 PM), and 4) Night (7:01 PM - 6 AM). ${ }^{3}$ Overall, the total recreation time for each individual is categorized into 14 activity type-location-time of day alternatives, corresponding to in-home recreation, out-of-home physically inactive recreation, and the 12 outof-home physically active recreation categories based on combinations of the three location

\footnotetext{
${ }^{3}$ The selection of the four time periods is primarily based on reflecting work-related constraints that may make it difficult for employed individuals to participate in recreation during certain times of the day. Further, our partitioning provides information on activity participation behavior during the AM and PM peak travel periods, which is useful from a travel modeling perspective. Of course, other time periods could also be used, but our partitioning seems also a rather natural one from a scheduling perspective. A descriptive analysis of all physically active recreational episodes showed that $76 \%$ of episodes beginning within any of these periods also ended within the same period. For the remaining $24 \%$ of episodes that straddle periods ( $40 \%$ of which had a duration of over 3 hours), the assignment of the episode's duration is split between time periods based on the duration of the episode in each time period.
} 
categories and four time-of-day periods. ${ }^{4}$ Finally, to determine the participation decision and the total amount of time expended in recreational activity (including in-home and out-of-home recreational pursuits) as part of the model system, we also define another "non-recreational" activity category with a time allocation computed as the difference between the total time available for recreational activity pursuits (defined as 24 hours minus the time allocated to work, work-related, and sleep activities) and the total time expended in recreational pursuits. Essentially, the inclusion of this additional non-recreational activity category (for a total of 15 activity categories) enables the endogenous treatment of total recreational time investment in our model system.

From a methodological standpoint, the model formulation used in the current analysis is the multiple discrete continuous extreme value (MDCEV) model developed by Bhat (2005, 2008). The model is capable of jointly predicting the discrete choice participation in, and the continuous choice of the time allocated to, each of the 15 activity alternatives identified above. In addition, the model is easy to estimate, and originates from a utility-theoretic and satiation view of time-use, which has a long and rich tradition in the economics and home science fields (for instance, see Gronau 1973, and Becker 1965; 1981). Some more relatively recent studies in the time-use/travel behavior field that have used the utility-theoretic/satiation perspective of time-use include Meloni et al., 2004, Bhat, 2005, Fang, 2008, and Habib and Miller, 2009. The MDCEV model uses a non-linear, additive, utility structure that is based on diminishing marginal utility (or satiation effects) with increasing participation duration in any of the 15 alternatives. That is, it is assumed that each of the activity categories represent "goods" that, when consumed (i.e., invested in in terms of time) provide positive utility. However, the marginal utility of time investment in any activity purpose diminishes with increasing time invested in that activity. The MDCEV model also allows corner solutions (zero consumption or no time investments) for the recreational activities. ${ }^{5}$

\footnotetext{
${ }^{4}$ The particular emphasis on physically active recreation in this paper is because of the obvious confluence of interest in this kind of recreation from both a public health perspective as well as a transportation perspective.

${ }^{5}$ As indicated above, the MDCEV model is based on a non-linear utility structure for each alternative. In such a structure, or any other utility-theoretic satiation-based structure, it becomes difficult to estimate the non-linear shapes of the utility functions when one alternative consistently (and across all individuals) "hogs" up a very large amount of time relative to other alternatives. This is the reason why we do not define the time allocated to the "nonrecreational" activity category as 24 hours minus the time spent on recreational pursuits (this would lead to very high durations for the "non-recreational" activity category). Rather, we remove out work, work-related, and sleep time durations from 24 hours, and use the resulting duration as the time available for participation in recreational
} 
The empirical analysis incorporates an extensive set of explanatory variables, including individual/household demographics and physical environment variables. While there is a vast body of literature on physical activity participation examining the first category of factors, there has been relatively scant attention on the physical environment determinants of physical activity, even though physical environment characteristics can significantly facilitate or constrain individuals' engagement in physical activity (see Duncan et al., 2005, Papas et al., 2007, and Bhat and Sener, 2009). The activity survey data used in the current study provide information on the residential location of each individual, which is used to develop measures of the physical environment variables in the family's neighborhood. The physical environment variables include (a) activity day and seasonal characteristics, (b) transportation system attributes, (c) built environment measures, and (d) residential neighborhood demographics (more on the variable specifications later).

The rest of the paper is structured as follows. The next section provides an overview of the model structure employed in the paper. Section 3 presents the data source, and discusses the sample formation procedure as well as important descriptive statistics of the sample. Section 4 presents the results of the empirical analysis, while Section 5 demonstrates the application of the model. Finally, Section 6 concludes the paper with a discussion of the results and the potential implications for intervention strategies aimed at promoting recreational physical activity.

\section{MODEL STRUCTURE}

In this section, we present an overview of the MDCEV model structure, which is used to examine adults' activity participation, and time investment, in each activity type-location-timing combination alternative (for ease in presentation, we will refer to the activity type-locationtiming combination alternatives simply as activity alternatives in the rest of this paper). The reader is referred to Bhat (2005) and Bhat (2008) for the intricate details of the model structure.

\subsection{Basic Structure}

Consider, without loss of generality, that the first activity alternative corresponds to the nonrecreational activity alternative. Since all sampled individuals invest some time on non-

pursuits, which then forms the basis for determining the time allocated to the "non-recreational" activity category, as discussed earlier. 
recreational activities over the weekdays, this alternative constitutes the "outside good" in the MDCEV model. ${ }^{6}$ The remaining additional 14 alternatives correspond to the different types of recreational activities, as described in the earlier section. Let $t_{1}$ be the non-zero amount of time invested in the non-recreational activity alternative, and let $t_{k}$ be the time invested in the recreational activity alternative $k(k=2, \ldots, K)$, where $K=15$ in the current empirical analysis. Consider the following additive, non-linear, functional form to represent the utility accrued by an individual through the weekday time investment vector $\boldsymbol{t}=\left\{t_{1}, t_{2}, \ldots, t_{K}\right\}$ in various activity alternatives (the index for the individual is suppressed in the following presentation): ${ }^{7}$

$U(\boldsymbol{t})=\frac{1}{\alpha_{1}} \exp \left(\varepsilon_{1}\right) t_{1}^{\alpha_{1}}+\sum_{k=2}^{K} \frac{1}{\alpha_{k}} \exp \left(\beta^{\prime} z_{k}+\varepsilon_{k}\right)\left\{\left(t_{k}+1\right)^{\alpha_{k}}-1\right\}$

$z_{k}$ is a vector of exogenous determinants (including a constant) specific to alternative $k$ (there is no such vector for the first alternative because only differences in utilities matter, as shown later). The term $\exp \left(\beta^{\prime} z_{k}+\varepsilon_{k}\right)$ represents the random marginal utility of one unit of time investment in alternative $k$ at the point of zero time investment for the alternative. This can be observed by computing the partial derivative of the utility function $U(\boldsymbol{t})$ with respect to $t_{k}$ and computing this marginal utility at $t_{k}=0$ (i.e., $\left.\partial U(\boldsymbol{t}) /\left.\partial t_{k}\right|_{t_{k}=0}\right)$. Thus, $\exp \left(\beta^{\prime} z_{k}+\varepsilon_{k}\right)$ controls the discrete choice participation decision in alternative $k$. We will refer to this term as the baseline preference for alternative $k . \alpha_{k}\left(\alpha_{k} \leq 1\right)$ is a satiation parameter whose role is to reduce the marginal utility with increasing consumption of alternative $k$. When $\alpha_{k}=1$ for all $k$, this represents the case of absence of satiation effects. Lower values of $\alpha_{k}$ imply higher satiation (or lower time investment) for a given level of baseline preference. The constraint that $\left(\alpha_{k} \leq 1\right)$ for $k=1,2, \ldots, K$ is maintained by reparameterizing $\alpha_{k}$ as $\left[1-\exp \left(\lambda_{k}\right)\right]$, where $\lambda_{k}$ is a scalar to be estimated. Further, to allow the satiation parameters to vary across individuals or households, we write $\lambda_{k}=\tau_{k}^{\prime} \omega_{k}$, where $\omega_{k}$ is a vector of individual/household-associated characteristics

\footnotetext{
${ }^{6}$ The term "outside good" refers to a good that is "outside" the purview of the choice of whether to be consumed or not. That is, the "outside good" is a good that is always consumed by all consumers.

${ }^{7}$ Several other additive, non-linear, utility forms, as proposed by Bhat (2008), were also considered. However, the one provided below was the best form (that is, provided by far the best data fit) in the empirical analysis of the current paper.
} 
impacting satiation for the $k^{\text {th }}$ alternative, and $\tau_{k}$ is a corresponding vector of parameters. Such a parameterization allows the discrete choice and the continuous choice decision of participation and duration of participation, respectively, to not be as tightly bundled together as would be the case if the satiation parameters are not allowed to be a function of exogenous variables.

From the analyst's perspective, individuals are maximizing random utility $U(t)$ on each weekday subject to the activity time budget constraint that $\sum_{k} t_{k}=T$, where $T$ is the total weekday time available for adults to participate in recreation activity. ${ }^{8}$ The optimal time investments $t_{k}^{*}(k=1,2, \ldots, K)$ can be found by forming the Lagrangian function (corresponding to the problem of maximizing random utility $U(\boldsymbol{t})$ under the time budget constraint $T$ ) and applying the Kuhn-Tucker (KT) conditions. After extensive, but straightforward, algebraic manipulations, the KT conditions collapse to (see Bhat, 2008):

$V_{k}+\varepsilon_{k}=V_{1}+\varepsilon_{1}$ if $t_{k}^{*}>0(k=2,3, \ldots, K)$

$V_{k}+\varepsilon_{k}<V_{1}+\varepsilon_{1}$ if $t_{k}^{*}=0(k=2,3, \ldots, K)$, where

$V_{1}=\left(\alpha_{1}-1\right) \ln \left(t_{1}^{*}\right)$ and $V_{k}=\beta^{\prime} z_{k}+\left(\alpha_{k}-1\right) \ln \left(t_{k}^{*}+1\right)(k=2,3, \ldots, K)$

Assuming that the error terms $\varepsilon_{k}(k=1,2, \ldots, K)$ are independent and identically distributed across alternatives with a type- 1 extreme value distribution, the probability that the adult allocates time to the first $M$ of the $K$ alternatives (for duration $t_{1}^{*}$ in the first alternative, $t_{2}^{*}$ in the second, $\ldots t_{M}^{*}$ in the $M^{\text {th }}$ alternative) is (see Bhat, 2008):

$P\left(t_{1}^{*}, t_{2}^{*}, t_{3}^{*}, \ldots, t_{M}^{*}, 0,0, \ldots, 0\right)=\left[\prod_{i=1}^{M} c_{i}\right]\left[\sum_{i=1}^{M} \frac{1}{c_{i}}\right]\left[\frac{\prod_{i=1}^{M} e^{V_{i}}}{\left(\sum_{k=1}^{K} e^{V_{k}}\right)^{M}}\right](M-1) !$

where $c_{1}=\left(\frac{1-\alpha_{1}}{t_{1}^{*}}\right)$ and $c_{i}=\left(\frac{1-\alpha_{i}}{t_{i}^{*}+1}\right)$ for $i=2, \ldots, M$.

\footnotetext{
${ }^{8}$ As discussed in Section 1.2, the total time available for recreational activities $(T)$ is computed as 24 hours minus the time invested in sleep, work, and work-related activities.
} 


\subsection{Mixed MDCEV Structure and Estimation}

The structure discussed thus far does not consider correlations among the error terms of the alternatives in the specification of the baseline preference. On the other hand, it is possible that such correlations exist. For instance, some adults may have a general predisposition (due to factors unobserved to the analyst) to participate in out-of-home pursuits, which can be reflected by an error-component specific to the baseline preferences of all the alternatives except the inhome recreation alternative. Alternatively, or in addition, some adults may have a predisposition to participate in physically active recreation at a certain activity location type such as a club or at a certain time of day such as the PM peak. The former effect can be accommodated through an error component specific to the baseline preferences of all physically active alternatives that include the club location (that is, an error component common to club-AM peak, club-Midday, club-PM peak, and club-night), while the latter effect may be captured through an error component specific to the baseline preferences of all physical active alternatives that include the PM-peak time of day (that is, an error component common to club-PM peak, neighborhood-PM peak, and outdoors-PM peak). Of course, the above examples are simply illustrative, and one can also test for several other patterns of error components. Such patterns of error components can be accommodated by defining appropriate dummy variables in the $z_{k}$ vector to capture the desired error correlations, and considering the corresponding $\beta$ coefficients in the baseline preference of the MDCEV component as draws from a multivariate normal distribution. The parameters to be estimated include the mean vector and variance matrix of the $\beta$ vector, and the $\tau_{k}$ parameters $(k=1,2, \ldots, K)$ that determine the satiation parameters $\alpha_{k}$. The parameters are estimated using a maximum simulated likelihood approach using Halton draws (see Bhat, 2003).

\section{DATA SOURCE AND SAMPLE DESCRIPTION}

\subsection{The Data}

\subsubsection{The Primary Data Source and the Construction of the Dependent Variables}

The primary source of data is the 2000 San Francisco Bay Area Travel Survey (BATS), which collected detailed information on individual and household socio-demographic and employmentrelated characteristics from about 15,000 households in the Bay Area (see MORPACE International Inc., 2002). The survey also collected information on all activity and travel episodes undertaken by individuals of the sampled households over a two-day period. The 
information collected on activity episodes included the type of activity (based on a 17-category classification system), the name of the activity participation location (for example, Jewish community center, Riverpark plaza, etc.), the type of participation location (such as in-home, health center, gym, or amusement park), and start and end times of activity participation.

The in-home recreation activity episodes were identified based on an activity being designated as "recreation" by the respondent and being indicated as pursued at home. The out ofhome physically active and physically inactive activity episodes were identified based on the activity type and the type of out-of-home participation location at which the episode was pursued, as reported in the survey. ${ }^{9}$ To be specific, the type of participation location (or location type for short) was collected in the BATS survey in an open response format, where respondents could write-in the location type of each participation. This resulted in about 10,000 location types, which were manually processed and consolidated into 450 location types. Of these, 23 location types were considered as being associated with physically active activity (see Bhat and Lockwood, 2004 for these location type categories). However, it is possible that individuals may be working at these sites (such as an individual working at a gym), and so our identification of whether an episode was physically active recreation or not was based on the location type being associated with physical activity as well as the respondent labeling the activity type as recreation. Subsequently, all other out-of-home episodes identified as recreation by the respondent, and not identified as physically active based on the procedure just discussed, were categorized as out-of-home physically inactive recreation episodes. Next, each out-of-home physically active episode was identified in one of three location types (club, neighborhood, or outdoors). The durations of each of the episodes were also computed based on the start and end times of the episode, and assigned to each time period as discussed in Section 1.2. The time investment contributions of all episodes in the day to each activity alternative were aggregated to obtain the total daily time investments in each of 14 recreation activity alternatives (in-home recreation, out-of-home physically inactive recreation, and the 12 out-of-home physically active recreation categories based on location and time-of-day). Finally, a non-recreation activity category is defined as discussed in Section 1.2, for a total of 15 activity alternatives. The

\footnotetext{
${ }^{9}$ A physically active episode requires regular bodily movement during the episode, while a physically passive episode involves maintaining a sedentary and stable position for the duration of the episode. For example, swimming or walking around the neighborhood would be a physically active episode, while going to a movie is a physically inactive episode.
} 
participation decisions, and the daily time investments, in these 15 alternatives constitute the dependent variables for the MDCEV model.

A few comments on our use of an activity survey are in order here. The motivation for the current paper originates at the interface of transportation and public health, as discussed in Section 1.2. In this regard, and as opposed to several earlier studies in the public health field that focus on measuring the intensity of physical activity, our emphasis is on the spatial and temporal aspects of physically active recreation. From this perspective, there are important advantages to using activity survey data because they provide detailed and complete information on the spatial and temporal dimensions of activity participation over the course of a day. In addition, activity survey data can be used to examine the potential effects of the built environment and the kinds of temporal constraints that may discourage physical activity participation. On the other hand, traditional physical activity studies focus on a single location setting (such as parks or playgrounds) for physical activity observation (see, for example, Reynolds et al., 2007), or collect information on a single continuous physical activity bout such as walking or bicycling (see, for example, Craig et al., 2002), or use sensor-based data collection systems for a single episode or a few episodes of a specific activity type (see, for example, Assah et al., 2011), or elicit long-term retrospective self-reports of participation and extent of participation in specific physical activities (see, for example, Mowen et al., 2007). These studies do not consider the possible range of physical activity locations and detailed time-of-day context information, nor do they typically collect information that would enable the examination of built environment impacts or the influence of temporal constraints. In fact, Dunton et al. (2008) lament on the inability of traditional physical activity measurement devices and methods to provide information on the spatial, temporal, and social contexts of physical activity participation, while highlighting the importance of such contextual information for designing customized physically active lifestyle promotion strategies. They then proceed to propose an activity survey as an additional approach to physical activity data collection that can complement traditional physical activity collection instruments and measurement techniques by providing contextual information as well as more comprehensive information on different types of physical activity bouts pursued during the course of a day. Of course, there are also limitations of activity surveys. For instance, the BATS survey used in the current paper does not provide information on in-home physical activity episodes. The survey also does not capture any measure of the intensity of physical 
activity. Further, the identification of physically active out-of-home recreation episodes is not perfect. For instance, the BATS data does not allow the distinction between individuals who are personally involved in the physical activity and those who are only present during the activity but not "physically" involved in the physical activity. Therefore, for instance, an episode designated as "recreation" activity by a respondent and pursued at a swimming pool is labeled as physically active, regardless of whether the individual went to the pool to watch some other person swim or swam himself/herself. ${ }^{10}$

To summarize, there are advantages and limitations to activity survey data in the context of physical activity analysis. But the synergy between the transportation and public health fields is at the confluence of the spatial, temporal, and built environment contexts of physical activity participations (see Doherty, 2009 and Mitra et al., 2010). From this standpoint, and notwithstanding some of the limitations of activity survey data, activity survey data constitute an important source of information for analysis. This is reflected in the many studies at the interface of the transportation and public health sciences fields that have used activity survey data as the basis for examining one or more aspects of physical activity participation.

\subsubsection{The Secondary Data Source}

In addition to the 2000 BATS survey data set, several other secondary data sets were used to obtain physical environment variables (particularly transportation system attributes, built environment characteristics, and residential neighborhood demographics) that may influence the physical activity participation, activity location, and activity timing/duration behavior of adults. All these variables were computed at the level of the residential traffic analysis zone (TAZ) of each household and considered in our model specifications. ${ }^{11}$ The secondary data sources included land-use/demographic coverage data, the 2000 Census of population and household summary files, a Geographic Information System (GIS) layer of bicycle facilities, a GIS layer of highways and local roadways, and GIS layers of businesses. Among the secondary data sets identified above, the land-use/demographic coverage data, LOS data, and the GIS layer of

\footnotetext{
${ }^{10}$ Note, however, that individuals who drop off/pick up others from the pool will report their activity type as "pickup/drop-off" and so this episode will not be considered as a physically active one, Also, there is some possibility that individuals who go to a pool and not swim will report their activity type as "social" or "resting/relaxing", in which case these episodes will also not be characterized as "physically active" in our taxonomy.

${ }^{11}$ Due to privacy considerations, the point coordinates of each household's residence are not available; only the TAZ of residence of each household is available. The average size of a TAZ is 9.7 square miles.
} 
bicycle facilities were obtained from the Metropolitan Transportation Commission (MTC). The GIS layers of highways and local roadways were obtained from the 2000 Census Tiger Files. The GIS layers of businesses were obtained from the InfoUSA business directory.

Among the physical environment variables, the zonal-level transportation system and built environment measures constructed from secondary data sources were as follows:

1. Transportation system attributes, including highway density (miles of highway facilities per square mile), local roadway density (miles of roadway density per square mile), bikeway density (miles of bikeway facilities per square mile), street block density (number of street blocks per square mile), non-motorized distance between zones (i.e., the distance in miles along walk and bicycle paths between zones), and transit availability. The non-motorized distance between zones was used to develop an accessibility measure by non-motorized modes, computed as the number of zones (a proxy for activity opportunities) within " $\mathrm{x}$ " nonmotorized mode miles of the adult's residence zone. Several variables with different thresholds for " $x$ " were formulated and tested.

2. Land use structure variables, including housing type measures (fractions of single family, multiple family, duplex and other dwelling units), land-use composition measures (fractions of zonal area in residential, commercial, and other land-uses), and a land-use mix diversity index computed as a fraction based on land-use composition measures with values between 0 and 1 (zones with a value closer to one have a richer land-use mix than zones with a value closer to zero; see Bhat and Guo, 2007 for a detailed explanation on the formulation of this index).

3. Regional accessibility measures, which include Hansen-type (Fotheringham, 1983) employment, shopping, and recreational accessibility indices that are computed separately for the drive and transit modes. The accessibility measures developed for each mode $m$ are as follows:

$$
A_{i m}^{\text {emp }}=\left[\sum_{j=1}^{N}\left(\frac{E_{j}}{t_{i j m}}\right)\right] / N, A_{i m}^{\text {shop }}=\left[\sum_{j=1}^{N}\left(\frac{R_{j}}{t_{i j m}}\right)\right] / N, \text { and } A_{i m}^{r e c}=\left[\sum_{j=1}^{N}\left(\frac{V_{j}}{t_{i j m}}\right)\right] / N,
$$

where $A_{i m}^{e m p}, A_{i m}^{\text {shop }}$, and $A_{i m}^{r e c}$ denote the employment, shopping, and recreational accessibility, respectively, for zone $i$ by mode $m ; E_{j}, R_{j}$, and $V_{j}$ are the number of basic 
employees, number of retail employees, and vacant land acreage, respectively, in zone $j$; $t_{i j m}$ is the travel time from zone $i$ to zone $j$ by mode $m$; and $N$ is the total number of TAZs.

4. Activity opportunity variables, characterizing the composition of zones in terms of the intensity or the density of various types of activity centers. The typology used for activity centers includes five categories: (a) maintenance centers, such as grocery stores, gas stations, food stores, car wash, automotive businesses, banks, medical facilities, (b) physically active recreation centers, such as fitness centers, sports centers, dance and yoga studios, (c) physically passive recreational centers, such as theatres, amusement centers, and arcades, (d) natural recreational centers such as parks and gardens, and (e) restaurants and eat-out places.

The residential neighborhood demographics constructed from secondary data sources were as follows:

1. Zonal population size and employment/population density measures, including total population, number of housing units, population density, household density, and employment density by several employment categories, as well as dummy variables indicating whether the area corresponds to a central business district (CBD), urban area, suburban area, or rural area.

2. Zonal ethnic composition measures, constructed as fractions of Caucasian, AfricanAmerican, Hispanic, Asian and other ethnic populations for each zone.

3. Zonal demographics and housing cost variables, including average household size, median household income, and median housing cost in each zone.

\subsection{Sample Description}

For the empirical analysis, only individuals aged 16 years or older were considered. Also, one weekday of the survey was selected for each adult, since the focus of the current analysis is exclusively on weekdays. The final estimation sample includes 13959 individuals residing in nine Counties of the San Francisco Bay Area (Alameda, Contra Costa, San Francisco, San Mateo, Santa Clara, Solano, Napa, Sonoma and Marin). As indicated before, all individuals in the sample participated in some amount of non-recreational (NR) activity, and this activity category serves as the "outside good" in our analysis. The mean duration of participation in NR is rather high (564 minutes or about 9.4 hours). Of the 13959 individuals, 9511 individuals participated only in non-recreational activity, while the remaining 4448 individuals participated 
in some combination of non-recreational activity and recreational activity. Table 1 presents the descriptive statistics of recreational activity participation among the 4448 individuals who participated in recreational activity. The first row of the table indicates that about $51 \%$ of these individuals participated in in-home recreation (IHR), with a mean weekday duration across individuals who participate in IHR being quite high at 221 minutes (about 3 hours and 40 minutes). The last four columns present information on the split between solo participations (i.e., participation in only the row activity alternative) and multiple activity alternative participations (i.e., participation in the row activity alternative and other activity alternatives). Thus, the results indicate that $77 \%$ of those who participate in IHR do not participate in any other recreation activity alternative during the weekday, while $23 \%$ of those who participate in IHR also participate in one or more of the remaining activity alternatives. The second and third rows of the table provide the corresponding figures for out-of-home physically inactive recreation (PIR) and out-of-home physically active recreation (PAR). In the third row, the figures for PAR represent a composite category, which is further broken down by location and time-of-day in subsequent rows (as we discuss later). The results of the second and third rows reveal a slightly higher participation rate in PAR (34\%) than in PIR (30.7\%) among those who participate in some form of recreation, though the mean time investment in PIR among those participating in PIR is higher than the mean time investment in PAR among those participating in PAR (117 minutes versus 100 minutes). Interestingly, the last two columns of the table indicate that about $71 \%$ of individuals who participate in PIR do not participate in IHR or PAR, while an almost identical percentage of individuals who participate in PAR do not participate in IHR or PIR.

The remaining rows in Table 1 provide more details of the PAR participation by location and time-of-day. ${ }^{12}$ The results indicate that the highest percentage of participation in PAR in terms of location is at a club, followed by participation in one's neighborhood. From a temporal standpoint, the highest PAR participation is in the midday period, while the lowest is in the night (note, however, that the length of time windows varies across the time-of-day periods; thus, from the perspective of PAR participation per time unit, there is higher PAR participation in the AM peak and PM peak periods than at other times of the day). As we will see later, an important

\footnotetext{
${ }^{12}$ The sum of the entries for the number of individuals participating in PAR alternatives across activity locations is greater than 1512 (the total number of individuals participating in PAR) because some individuals may participate in PAR at multiple locations in the same day. The same is true for the number of individuals participating in PAR alternatives across times-of-day because some individuals may participate in PAR during multiple time periods of the weekday.
} 
variable determining temporal patterns of PAR participation is employment, with unemployed individuals more likely than those employed to participate in the midday period. The mean duration of PAR participation is highest when pursued outdoors, and shortest when pursued in/around the residential neighborhood. In terms of time-of-day, the mean duration of PAR participation shows little variation across the day-time temporal periods (AM peak, midday, and PM peak), though the mean duration is shorter for PAR participation in the night relative to the day-time periods. The last two main columns corresponding to the PAR alternatives reveal that those who pursue PAR in their neighborhoods are also most likely to participate in other PAR alternatives or IHR or PIR, while those participating in PAR at clubs are the least likely to participate in other PAR alternatives or IHR or PIR. Also, in addition to participation in nonrecreational activity, note that a significant proportion of individuals participate in multiple alternatives among the 14 recreational alternatives considered in the current paper, as should also be clear from the entries in the final column of Table 1. This highlights the need for, and appropriateness of, the MDCEV model for the current analysis.

Table 1 only shows the aggregate distribution of participation in PAR separately along each of the location and time-of-day dimensions. On the other hand, in the current paper, we focus on the interactions of location and time-of-day for PAR activities. In Table 2, we present the participation levels in PAR by location and time-of-day. The first two number columns (for locations) and the first number row (for time-of-day) provide the one-dimensional participation statistics, while the rest of the table presents the descriptive statistics for each combination alternative. For instance, the first number in the combination part of the table indicates that 134 individuals participate in PAR at a club during the AM peak period. This corresponds to $20.2 \%$ of all adults participating in PAR at a club, and 33.8\% of all adults participating in PAR during the AM peak period of the weekday (note that the percentages for each row (column) across activity locations (times-of-day) can sum to more than $100 \%$ due to multiple discreteness; for instance an adult can go to a club for weight-training during the AM peak period and then play tennis at a club with a friend in the night period. In general, the results in Table 2 show that the midday period is the most likely one for pursuing PAR at a club or outdoors, while the AM peak period is the most likely time-of-day for pursuing PAR in and around one's neighborhood. Also, the most frequent PAR location during each time-of-day is as follows: AM peak - in/around one's neighborhood, midday - club, PM peak - club, and night - club. 


\section{MODEL RESULTS}

\subsection{Variable and Error-Components Specification}

A number of variables within the two broad variable categories of individual/household factors and physical environment correlates were considered in our model specification. The final variable specification was based on a systematic process of eliminating variables found to be statistically insignificant, intuitive considerations, parsimony in specification, and results from earlier studies. Several different variable specifications, functional forms of variables as well as interaction variables were examined. The specification includes some variables that are not highly statistically significant, because of their intuitive effects and potential to guide future research efforts in the field. In addition to alternative variable specifications, we also considered several error-component structures to generate correlation in the unobserved error terms of the baseline utilities of the 15 alternatives. But the only one that turned out to be statistically significant was a common error component across alternatives that included the "neighborhood" location.

\subsection{Estimation Results}

The final specification results of the mixed MDCEV model are provided in Tables 3 and 4 . Table 3 presents the results of the parameter estimates corresponding to the baseline preference utility (the $\beta$ parameter vector in Equation 1), while Table 4 presents the results of the satiation parameters (the $\tau_{k}$ parameter vector in the actual satiation parameter $\alpha_{k}$ ). The non-recreational activity alternative serves as the base category for all variables (and, thus, this alternative does not appear in the tables as a row). In addition, a '-' entry in Table 3 under a particular activity alternative for a particular variable implies that this variable is omitted from the utility specification for that alternative (that is, the alternative also constitutes a base alternative about which the impact of the variable on other alternatives should be interpreted). Also, note that, for dummy exogenous variables, it is implicit that the omitted dummy variable category (or categories) serves (serve) as the baseline reference.

The results for the baseline preference specification for the in-home recreation (IHR) and the out-of-home physically inactive recreation (PIR) alternatives are presented in the first two rows. For the out-of-home physically active recreation (PAR) alternative, the effect of each variable is first identified separately along the location and time-of-day dimensions. The final 
row panel of the table identifies any interaction effects of each variable on the PAR baseline utility for each location-time of day combination alternative over and above the one-dimensional location/time-of-day effects. ${ }^{13}$

\subsubsection{Individual Demographics}

Among individual demographics, the gender-related effects indicate that women are less likely than men to participate in weekday IHR activities and PAR activities, and more likely to participate than men in non-recreational and PIR activities. The lower PAR activities of women relative to men have been consistently highlighted in the literature (see, for instance, Trolano et al., 2008). The coefficients implicitly also suggest that women (relative to men) are more likely to participate in PIR activities (than in IHR and PAR activities). This higher participation level of women in PIR activities is consistent with the findings from several earlier studies indicating that women are more involved with arts/crafts shows, concerts, museums and related "high-culture" activities (see Srinivasan and Bhat, 2006 and Nakai, 2009). However, the results also show that women have a stronger tendency to pursue PAR activities in the AM and PM peak periods relative to other time periods of the day. Of course, one should keep in mind that the measure of physical activity in our study is the duration of time spent in physical activity on a single weekday as self-reported in a general activity survey, while several earlier studies have considered time expended in physical activity over longer stretches of time (such as a week or a longer period of time) using focused physical activity surveys or objective measurements of physical activity.

The age effects indicate the lower baseline preference of individuals less than 30 years of age (compared to their older peers) to participate in PAR activities in/around residences (except in the PM peak period). The same is true for participation in PAR outdoors in the AM peak and midday periods, though young adults are more likely than their older peers to participate in PAR outdoors during the PM peak (the net effect on the baseline utility for the PAR outdoor-PM peak alternative is $-0.29+0.94=+0.65$ ). Also, the results indicate that young adults have a much higher preference than their older peers to participate in PAR at clubs in the PM peak and night periods. Similar results of higher preference for participation in PAR during the PM peak period

\footnotetext{
${ }^{13}$ To conserve on space, we do not present the baseline preference constants in Table 3 . These constants do not have any substantive interpretations, but absorb the impacts of the different lengths of the time-of-day periods.
} 
(except in/around neighborhoods) can also be observed for those in the 30-49 years age group relative to the " 50 years or more" age group category, though the effect is less pronounced than for the youngest age group. ${ }^{14}$ Dunton et al. (2008) found similar results of age-based preferences for PAR location. In general, the tendency among younger individuals to pursue PAR at clubs and of older individuals to pursue PAR in neighborhoods may be a reflection of generational differences. Since clubs were not very common or well dispersed until the 1980's and 1990's, older generations of adults are probably used to engaging in physical activities outside of clubs. Therefore, these individuals may simply perceive no need or reason for exercising at a club. On the other hand, younger adults are likely to be more familiar with the physical activity options available at clubs and may also view club-based PAR as a social activity. Caspersen et al. (2000) also notes that strengthening exercises, which may be particularly facilitated by the use of machines available at a club, dramatically declines with age, which may explain the lower PAR participation of older adults at clubs. However, it is still not clear whether older individuals, in general, do not partake in strengthening exercises as often as their younger peers and therefore do not go to clubs, or simply do not go to clubs and therefore partake less in strengthening exercises.

The physical disability status of individuals is a strong deterrent factor for both PIR and PAR activities. In particular, the results show that physically disabled adults are less likely to participate in out-of-home recreation regardless of the nature, location or time-of-day of the activity). Also, these individuals are particularly not likely to participate in PAR activities during peak hours, perhaps because they would rather avoid dense traffic conditions.

The remaining individual demographic effects indicate the lower preference of full-time students to participate in PAR during the AM peak period relative to other time periods, presumably because of school-time constraints. This result might also be a reflection of a typical "shifted day" that an adult student adopts, with a late start to the day and with activities stretching into the late night hours. Finally, adults with a driver's license are less likely (relative to adults without a driver's license) to participate in PAR in their neighborhood. This result is to

\footnotetext{
${ }^{14}$ Several different threshold values were attempted to capture non-linear age-related effects in our dummy variable specification, but the thresholds of 30 years and 49 years provided the best fit. In addition, this dummy variable specification was better than a continuous age specification and a specification that considered non-linear spline effects.
} 
be expected, because individuals with a driver's license have an increased opportunity to drive to physical activity locations outside their neighborhood.

\subsubsection{Work-Related Characteristics}

The effects of work-related characteristics are quite intuitive. First, employed adults have a higher propensity than those unemployed to participate in PAR at a club rather than participating at PAR at other locations. Perhaps, employed individuals tend to attend gym facilities at or within close proximity of their employment locations. They are also likely to find the showering and locker facilities at clubs to be convenient. Second, employed adults (relative to nonemployed adults) have a lower baseline utility preference to partake in physical activities during the AM peak and midday periods than in other time periods of the weekday. This clearly reflects the employed individual's perceived or real obligation to work during the traditional workday hours (that is, $8 \mathrm{AM}$ to $5 \mathrm{PM}$ ). Finally, the work flexibility variable effects indicate a progressively higher baseline propensity of individuals with increasing flexibility to pursue PAR at clubs, though workers with more work flexibility are less likely to pursue PAR during the midday period. This latter result may reflect a desire to use the work-day efficiently for different activity participation needs, which, for individuals with flexible work schedules is likely to imply earlier or later PAR participation and a core uninterrupted work period during the midday. Overall, the work-related effects suggest that effective policy interventions to encourage PAR among workers would provide club facilities in/around work centers, since employed adults appear to be predisposed to exercise in clubs if such an option is conveniently available from a spatial and temporal standpoint.

\subsubsection{Household Demographics}

Among the household demographics, the nuclear family variable indicates a lower propensity of adults in nuclear families (relative to adults in other families such as single parent families and families with no children) to participate in in-home recreation compared to non-recreation and out-of-home recreation, perhaps a reflection in nuclear families of the increased opportunities for one or both parents to pursue joint out-of-home recreation with children (see also Bhat and Lockwood, 2004 and Sener et al., 2010 for similar results). These results are reinforced by the age-specific effects of children, which suggest that the presence of young children (aged 0-4) in 
the household increases PAR during the midday, especially outdoors (at parks) (see bottom row of Table 3 under the column “Aged 0-4”). On the other hand, adults with older children (aged 515) are likely to avoid participation in physical activity during the peak time periods compared to other time periods of the day. This is presumably because of the responsibilities of adults associated with preparing school-age children for school and/or transporting them to/from school.

As continually underscored in the literature, individuals living in low income households (those with an annual income less than $\$ 35,000$ ) have a higher propensity than those in middle or high income households to engage in in-home recreation (IHR) activities, perhaps due to financial constraints. The implication is that individuals in low income households participate less than those in middle-to-high income households even in physically active recreation (PAR) activities in their immediate neighborhoods. Since PAR in neighborhoods should not have substantial financial implications to individual families, this result is another indication that the quality of the environment in which low income households reside appears to have an impact on PAR. As stated by Bennett et al. (2007), "residing in a neighborhood that is perceived to be unsafe at night is a barrier to regular physical activity among individuals, especially women, living in urban low-income housing. Feeling unsafe may also diminish confidence in the ability to be more physically active.” The income-related effects also point to the higher propensity of high income households to participate in PAR at clubs, probably due to financial ability.

Individuals from households owning one or more vehicles have a higher propensity to engage in physically inactive recreation (PIR) activities relative to individuals from households with no vehicles, according to the results in Table 3. Individuals with more vehicles in their household are also more likely to participate in outdoors PAR recreation except in the PM peak period. In addition, although the results reveal a strong negative effect for PAR participation during the PM peak period, this effect is less pronounced when pursued at clubs. Finally, in the class of household demographics, bicycle ownership is found to be a motivator for increased PAR in/around an individual's neighborhood. These vehicle (bicycle)-based effects need to be examined more carefully in future studies to account for self-selection effects, because vehicle/bicycle ownership may be endogenous to PAR activity (that is, individuals and households who are PAR-oriented may consciously make the choice of owning fewer vehicles and/or more bicycles in the first place). 


\subsubsection{Physical Environment Variables}

The seasonality effects within the group of physical environment variables reveal the increased tendency to stay at home for recreation activities during the winter season, and a higher predisposition to participate in outdoor PAR activities during the summer season (see also, Tucker and Gilliland, 2007 and Sener and Bhat, 2007 for such seasonal effects). ${ }^{15}$ These results suggest a need to target physical activity promotion campaigns during the winters toward ways to increase in-home physical activity, and/or on providing accessible and inexpensive indoor club facilities.

In the category of transportation system attributes/built environment characteristics, very few variables turned out to be statistically significant, suggesting that, in general, participation in PAR may be more of a lifestyle choice than related to the availability of spatial opportunities for PAR participation. ${ }^{16}$ But, accessibility to physical activity centers in the residence zone of an individual has clear positive impacts on PAR at clubs. Furthermore, the density of bikeway has the expected positive influence on PAR in the neighborhood when interacted with bicycle ownership in the household. This result has also been documented in some earlier studies (see, for instance, Pinjari et al., 2009 and Cervero and Duncan, 2003). Of course, one should view these built environment and bicycle ownership effects with some caution because we have not considered potential residential self selection effects. That is, it is possible that highly physically active families will own more bicycles and will self-select themselves into zones with built environment measures that support their active lifestyles (see Bhat and Guo, 2007, Pinjari et al., 2008, and Bhat and Eluru, 2009 for methodologies to accommodate such self selection effects; combining such methodologies with the MDCEV model of spatial and temporal dimensions of PAR behavior developed here is left for future research).

With respect to zonal demographics, the results indicate the lower participation in IHR activities as well as the higher participation in PAR activities (particularly at clubs and outdoor locations) among Caucasian Americans compared to other races. This result is consistent with

\footnotetext{
${ }^{15}$ Of course, these seasonality findings are based on the San Francisco region. While the results are likely to be transferable to a good part of the rest of the U.S., they may not be transferable to some parts of the U.S. that, for example, may get very hot and sticky during the summer with milder temperatures during the Spring/Fall seasons.

${ }^{16}$ However, the result that many built environment variables did not turn out to be statistically significant may also be a manifestation of the use of the TAZ as the spatial unit of resolution for computing transportation system/built environment variables. Future studies should consider more micro-scale measures to represent neighborhood physical environment variable effects, which would require some kind of geo-coded information on household residences.
} 
several previous studies (see Gordon-Larsen et al., 2005 and 2006). Research studies aimed at better understanding the reasons for these race-based differences in PAR participation may help in the design of targeted PAR promotion campaigns. Finally, individuals residing in zones with a high mean household income are more likely to participate in PAR activities at clubs.

\subsubsection{Satiation Parameters}

As discussed in Section 2.1, the satiation parameters $\alpha_{k}(k=1,2, \ldots, K)$ are written as $\left[1-\exp \left(\tau_{k}^{\prime} \omega_{k}\right)\right]$, where $\omega_{k}$ is a vector of individual/household characteristics impacting satiation for the $k^{\text {th }}$ alternative, and $\tau_{k}$ is a corresponding vector of parameters to be estimated. Table 4 provides estimates of the elements of the $\tau_{k}$ vector. Positive values of the $\tau_{k}$ elements imply higher satiation associated with larger values of the corresponding elements of $\omega_{k}$. Note also that the $\tau_{k}$ vector includes a constant for each $k(k=1,2, \ldots, K)$, though these 15 constants are not included in the table to conserve on space. ${ }^{17}$

As observed from the results in Table 4, we did not find many highly statistically significant coefficient effects for the satiation parameters. However, the results show that, at a moderate significance level, there are variations in satiation for out-of-home activity categories across individuals. ${ }^{18}$ Table 4 indicates that women have a higher satiation (lower participation durations) than men in PIR and outdoor PAR categories, except the PM peak period. In addition, the age effects indicate lower satiation (higher participation durations) for younger individuals than for older individuals for evening PAR participations. Other results in Table 4 may be similarly interpreted. As importantly, one can notice from Tables 3 and 4 that the activity participation decision and the amount of activity participation are not always tied tightly together. For instance, from Table 3, we note that, compared to men, women have a lower baseline preference for participation in in-home recreation (IHR) activity; however, from Table

\footnotetext{
${ }^{17}$ However, we should note that, when only a constant was included in the specification of $\omega_{k}$ for each $k$, the resulting imputed values of $\alpha_{k}$ were all highly statistically significantly less than the value of 1 , indicating clear evidence of satiation effects and support for the use of the MDCEV model. In this constants-only specification in satiation, the satiation parameters were generally consistent with the sample statistics in Table 1 . For instance, the results showed that PAR pursued in/around residential neighborhoods have higher satiation levels compared to PAR pursued at clubs and outdoor parks/recreational areas.

${ }^{18}$ We did not find any statistically significant satiation variations (for the non-recreation (NR) and in-home recreation (IHR) categories, because the variations in the durations of time investments in these categories were small relative to the overall high magnitude of durations in the categories.
} 
4, we notice no satiation differences based on gender for IHR activity. The age effects for the night PAR activities and the employment effects for club PAR activities, are reinforcing in the baseline preference effects and the satiation effects. But, the employment effects for AM peak PAR activities are not reinforcing. Thus, employed individuals tend to have a lower baseline propensity (than unemployed individuals) for participation in PAR activities during the AM peak period, but have a lower satiation for participation (high participation duration) in PAR activity during the AM peak period. Essentially, this lends support to not tying the discrete participation and continuous time duration decisions too tightly.

\subsubsection{Error Components}

The final specification included only one error component specific to the "neighborhood" location. This error component has a standard deviation of 2.72 with t-statistics of 21.87, indicating the existence of common unobserved factors that predispose adults to participate in physical activity in/around their neighborhood regardless of time-of-day.

\subsubsection{Likelihood-Based Measures of Fit}

The log-likelihood value at convergence of the final mixed MDCEV model is -57175.9. The corresponding value for the model with only the constants in the baseline preference, the

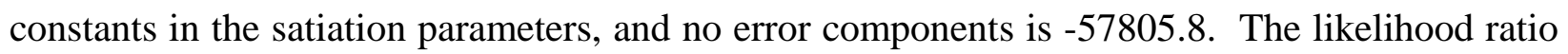
test for testing the presence of exogenous variable effects on baseline preference and satiation effects, and the presence of error components, is 1259.8, which is substantially larger than the critical chi-square value with 52 degrees of freedom at any reasonable level of significance. In addition, the rho-bar squared value, computed with respect to the constants-only model is 0.0109, while the adjusted rho-bar squared value, computed with respect to the constants-only model, is $0.0100 .^{19}$ Overall, the results indicates the value of the model estimated in this paper to predict adults' recreational activity time use by location and time-of-day, based on individual demographics, work-related characteristics, household demographics, and physical environment variables.

\footnotetext{
${ }^{19}$ These fit values should not be perceived as being low, because these are for a multiple discrete-continuous choice model, with all combinations of choices from the 15 discrete alternatives possible for an individual. In the current empirical context, each individual has a total of $2^{15}-1=32767$ combinations to choose from. And then there is also the continuous component for each of the combinations.
} 


\section{MODEL APPLICATION}

In this paper, we demonstrate the application of the model by studying the effects of selected variables. These variables (and the change in the variables that are examined) are as follows: (1) decrease in the number of 'individuals younger than 50 years of age' (25\% decrease), (2) increase in the number of 'households with kids less than 16 years of age' (25\% increase), (3) increase in 'vehicle ownership' for each household (increase by one vehicle), (4) increase in 'accessibility to physical activity centers' (25\% increase), (5) increase in 'bikeway density in the zone interacted with the number of bicycles in the household' of each household (25\% increase), and (6) decrease in the fraction of 'Caucasian American population' in the zone of residence of each household (25\% decrease). The decrease in the number of individuals younger than 50 years of age (to reflect aging of the U.S. population) is obtained by randomly selecting current individuals younger than and equal to 50 years of age in the sample, and assigning them as individuals older than 50 years of age so that the number of individuals younger than 50 years of age decreases by $25 \%$. The $25 \%$ increase in the number of households with kids less than 16 years of age is also implemented in a similar fashion. Finally, the changes for the remaining four policies are applied to each household in the final sample.

The time-use prediction was undertaken with the MDCEV formulation using 100 sets of error term draws for each individual, based on the efficient forecasting procedure developed by Pinjari and Bhat (2010). To examine the impact of the aforementioned changes, we estimate the predicted aggregate time-use patterns before and after the changes, and compute an effective percentage change from the baseline parameter estimates. The effect of the changes on aggregate time-use patterns is measured as the net percentage change in the duration of participation in each activity alternative across all individuals. Also, to obtain standard deviations of the estimated magnitude effects, we undertake a bootstrap procedure using 50 draws of the coefficients (on the exogenous variables) based on their estimated sampling distributions. Note that, in the application exercises, we present the effects of variables separately on the location and time dimensions for PAR activities. We do so simply for presentation ease (to avoid having 15 alternatives in the results table), though our model actually produces time-use predictions for combinations of the location and time dimensions.

Table 5 provides the prediction results (that is, the net percentage change in time-use in activity alternative categories across all individuals) for each of the six scenarios described 
earlier. A "-" entry in the table indicates changes less than $0.1 \%$ along the activity alternative categories. The mean magnitude effect across the 50 bootstrap draws is in the column labeled "Mean" and the standard deviation of the magnitude effect is in the column labeled "Std. Dev.". For instance, the first number "-14.76" with a standard deviation of " 4.32 " corresponding to the "age less than 50 years" variable in the final model indicates that the overall time-use in PAR activities at clubs decreases by about 15\% (with a standard deviation of this effect being $4.32 \%$ ) if the percentage of adults less than 50 years decreases by $25 \%$ (with a corresponding increase in the percentage of adults 50 years of age or older). Also, the results show that there is a decrease in PAR activity pursued outdoors (at parks), and a decrease in time spent in PAR activity during the PM peak by $24.13 \%$ and during the night period by $10.17 \%$ due to the change in age distribution. These predicted changes are consistent with the results discussed in Section 4.2.1.

Several important observations may be made from Table 5. First, the results indicate that demographic variables have important effects on the time spent in PAR activities. In addition to the age effects just discussed, the presence of children (aged less than 16 years) in households results in decreased levels of adults' PAR activities, especially those pursued in/around neighborhoods and during the PM peak period. Second, an increase in household vehicle ownership increases time spent in PIR activities, and has a very high negative impact on the time spent in PAR activities in/around individuals' neighborhoods and during the PM peak period. In particular, an additional vehicle leads to about 5\% increase in the time spent in PIR activities, while also resulting in about $66 \%$ and $96 \%$ decreases in the time spent in PAR activities in/around individuals' neighborhood and during the PM peak period, respectively. Interestingly, but consistent with the model estimation results, the increase in household vehicle ownership also results in an increase in the time spent in PAR activities pursued outdoors (at parks), perhaps because it increases the accessibility to outdoor activity centers (such as parks or health centers). This latter result indicates the importance of examining different recreational activity categories simultaneously (that is, physically active and physically inactive activities) and at a disaggregate level (based on the type, location, and timing of the activity) to capture the effects of variables accurately. Third, physical environment variables are found to have important impacts on activity time use. A 25\% increase in the accessibility to physical activity centers leads to a rather substantial (about $46 \%$ ) increase in PAR time at clubs, while a $25 \%$ increase in zonal bikeway density significantly increases (by about 75\%) the time spent in PAR activities in and 
around neighborhoods. All these results are consistent with those in the previous section; however, as indicated in the previous section, these results and effects need to be further examined carefully in future studies to account for self-selection effects. Finally, a decrease in the Caucasian-American population leads to a general increase in in-home recreation time-use and a decrease in PAR activity time-use across all activity locations and time-of-the-day. This is an issue that obviously deserves further examination and attention, particularly because the U.S. population is becoming more racially and ethnically diverse.

Overall, the model application reveals the value of the model in capturing the changes in the time use patterns of individuals under different scenarios, and highlights the importance of using the MDCEV model in such an analysis.

\section{CONCLUSIONS AND IMPLICATIONS}

The main objective of the current study was to propose and apply a modeling framework to examine individuals' time-use in non-recreation (NR), in-home recreation (IHR), out-of-home physically inactive recreation (PIR), and out-of-home physically active recreation (PAR). The empirical results and model application provide several insights for the design of targeted interventions to promote physical activity. First, young adults are more likely to participate in PAR at clubs during the PM peak periods, while older adults are more likely to participate in PAR in and around their neighborhoods during non-PM peak time periods. Thus, interventions aimed at promoting PAR among young adults would benefit from promoting club-related opportunities and offering special classes (such as yoga, pilates, aerobics, weight-training, etc.) at these clubs during the PM peak period. On the other hand, residential areas with a high fraction of middle-aged to senior adults would benefit from a well-planned network of pedestrian and bicycle pathways that are conducive to PAR in/around neighborhoods. Second, employed adults have a high preference to partake in PAR at clubs during the PM peak period (4 PM - 7 $\mathrm{PM})$, suggesting that employers can play a role in promoting PAR among their employees by providing fitness center facilities at the work place and/or providing subsidies for club membership at fitness centers within close proximity to the work place. Further, staggering work hours to an early start and an early end to the work day (say, for example, a 7 AM - 4 PM schedule rather than a $8 \mathrm{AM}$ - 5 PM schedule) may provide beneficial results by providing more time in the afternoon (and before dinner time) to invest in PAR. Third, as in several earlier 
studies, our study also points to the lower PAR among adults in low income households and those residing in neighborhoods with a high fraction of non-Caucasians. While the reasons for these results need to be explored further in future studies, the results suggest a need for targeted campaigns to increase awareness about physical activity benefits in neighborhoods with a significant fraction of low-income households and/or non-Caucasian households. Further, it is important to pursue efforts to evaluate current facilities for PAR, and invest in improved facilities and PAR opportunities, in low income and/or non-Caucasian neighborhoods. This is an issue that needs top priority, especially because there is evidence from earlier research (see Davison et al., 2003, Trost et al., 2003, Davis et al., 2007, and Sener et al., 2010) that children explicitly mimic their parents' physical activity participation. This finding in the literature, combined with the decreasing share of the Caucasian population in the U.S. and the increasing share of the non-Caucasian population, implies that there could be a "ripple" effect in physical inactivity levels over the next few generations of the U.S. population, unless quick and immediate steps are taken to "nip physical inactivity in the bud" among adults in the U.S. population in general, and in non-Caucasian adults in particular. Fourth, interventions targeted toward year-round physical activities should benefit from promoting home-based physical activity in the winters, given the tendency to pursue recreational activities at home during the cold season. Finally, and not withstanding residential self-selection issues, our results suggest the positive PAR benefits of improved bicycle facilities and accessible physical activity centers (or clubs) in/around residences. These built environment effects do point to the need for the design of near term, feasible, and effective urban form strategies that promote compact and mixed landuse designs with good bicycling facilities.

In addition to the implications of the research results for public health policies, the model developed in the paper can be used as part of activity-based travel frameworks for forecasting purposes. For example, in the Comprehensive Econometric Microsimulator for Daily Activitytravel Patterns (CEMDAP; see Pinjari et al., 2006), one of the modules of the activity generation stage corresponds to the prediction of recreational activity participations of individuals. The model in this paper can readily be integrated for this purpose. Further, and as noted earlier, the underlying motivation and behavior of recreational activity participation as well as the travel for recreational activities are quite different than that of other activity purposes. Therefore, activitybased travel demand forecasting tools would significantly benefit from incorporating the spatial 
and temporal contexts of recreational activity participation as identified in the proposed model. More generally, and as indicated in Pinjari and Bhat (2010) "activity time-use analysis is concerned with understanding how individuals use (or allocate) the time available to them among various activities and travel. Such an analysis is central to the activity-based approach to travel modeling, because, in this approach, individuals' activity-travel patterns are viewed as a result of their activity time-use decisions...”.

Overall, this paper contributes to the growing research at the interface of the transportation and public health fields to examine activity participation and time-use in active transportation and recreation. The paper also underscores the importance of examining the spatial and temporal contexts of physical activity participation for informed physical activity promotion and activity-based travel analysis.

\section{ACKNOWLEDGEMENTS}

The authors are grateful to Lisa Macias for her help in formatting this document. The authors acknowledge the helpful comments of three anonymous reviewers on an earlier version of the paper. The authors would also like to acknowledge Abdul Pinjari's assistance in the model application section, and the help of Erin Ferguson in preliminary data assembly and analysis. 


\section{REFERENCES}

Assah F.K., Ekelund U., Brage S., Wright A., Mbanya J.C., Wareham N.J. (2011) Accuracy and validity of a combined heart rate and motion sensor for the measurement of free living physical activity energy expenditure in adults in Cameroon. International Journal of Epidemiology 40(1): 112-120.

Becker G.S. (1965) A theory of the allocation of time. Economic Journal 75: 493-517.

Becker G.S. (1981) A Treatise on the Family. Harvard University Press, Cambridge, MA.

Bennett G.G., McNeill L.H., Wolin K.Y., Duncan D.T., Puleo E., Emmons K.M. (2007) Safe to walk? Neighborhood safety and physical activity among public housing residents. PLoS Medicine 4(10): 1599-1607.

Bhat C.R. (2003) Simulation estimation of mixed discrete choice models using randomized and scrambled Halton sequences. Transportation Research Part B 37(9): 837-855.

Bhat C.R. (2005) A multiple discrete-continuous extreme value model: formulation and application to discretionary time-use decisions. Transportation Research Part B 39(8): 679707.

Bhat C.R. (2008) The multiple discrete-continuous extreme value (MDCEV) model: role of utility function parameters, identification considerations, and model extensions. Transportation Research Part B 42(3): 274-303.

Bhat C.R., Eluru N. (2009) A copula-based approach to accommodate residential self-selection effects in travel behavior modeling. Transportation Research Part B 43(7): 749-765.

Bhat C.R., Gossen R. (2004) A mixed multinomial logit model analysis of weekend recreational episode type choice. Transportation Research Part B 38(9): 767-787.

Bhat C.R., Guo J.Y. (2007) A comprehensive analysis of built environment characteristics on household residential choice and auto ownership levels. Transportation Research Part B 41(5): 506-526.

Bhat C.R., Lockwood A. (2004) On distinguishing between physically active and physically passive episodes and between travel and activity episodes: an analysis of weekend recreational participation in the San Francisco Bay Area. Transportation Research Part A 38(8): 573-592.

Bhat C.R., Sener I.N. (2009) A copula-based closed-form binary logit choice model for accommodating spatial correlation across observational units. Journal of Geographical Systems 11(3): 243-272.

Cao X., Handy S.L., Mokhtarian P.L. (2006) The influences of the built environment and residential self-selection on pedestrian behavior: evidence from Austin, TX. Transportation 33(1): 1-20.

Caspersen C.J., Pereira M.A., Curran K.M. (2000) Changes in physical activity patterns in the United States, by sex and cross-sectional age. Medicine \& Science in Sports \& Exercise 32(9): 1601-1609. 
Centers for Disease Control and Prevention (CDC) (2006) Youth risk behavior surveillance United States, 2005. Morbidity and Mortality Weekly Report, 55(SS-5).

Cervero R., Duncan M. (2003) Walking, bicycling, and urban landscapes: evidence from the San Francisco Bay Area. American Journal of Public Health 93(9): 1478-1483.

Cohen D.A., McKenzie T.L., Sehgal A., Williamson S., Golinelli D., Lurie N. (2007) Contribution of public parks to physical activity. American Journal of Public Health 97(3): 509-514.

Copperman R., Bhat C.R. (2007) An analysis of the determinants of children's weekend Physical activity participation. Transportation 34(1): 67-87.

Craig C.L., Brownson R.C., Cragg S.E., Dunn A.L. (2002) Exploring the effect of the environment on physical activity. A study examining walking to work. American Journal of Preventative Medicine 23(2 Suppl): 36-43.

Davis M.M., Gance-Cleveland B., Hassink S., Johnson R., Paradis G., Resnicow K. (2007) Recommendations for prevention of childhood obesity. Pediatrics 120(suppl4): S229-S253.

Davison K.K, Cutting T.M., Birch L.L. (2003) Parents' activity-related parenting practices predict girls’ physical activity. Medicine \& Science in Sports \& Exercise 35(9): 1589-1595.

Devlin A., Frank L., vanLoon J. (2009) Physical activity and transportation benefits of walkable approaches to community design in British Columbia. Prepared for the British Columbia Recreation and Parks Association, Burnaby, BC.

http://gw.city.vancouver.bc.ca/parks/activecommunity/pdf/BCRPA_Transportation_Study_2 009.pdf

Doherty S. (2009) Emerging methods and technologies for tracking physical activity in the built environment. In: Bonnel P., Lee-Gosselin M., Zmud J., Madre J.L. (eds), Transport survey methods: keeping up with a changing world, Emerald Group Publishing Limited, Bingley, UK, pp 153-190.

Duncan M.J., Spence J.C., Mummery W.K. (2005) Perceived environment and physical activity: a meta-analysis of selected environmental characteristics. International Journal of Behavioral Nutrition and Physical Activity 2(11): 1-9.

Dunton G.F., Berrigan D., Ballard-Barbash R., Graubard B.I., Atienza A.A. (2008) Social and physical environments of sports and exercise reported among adults in the American Time Use Survey. Preventive Medicine 47(5): 519-524.

Fang H.A. (2008) A discrete-continuous model of households' vehicle choice and usage, with an application to the effects of residential density. Transportation Research Part B 42(9): 736758.

Fotheringham A.S. (1983) Some theoretical aspects of destination choice and their relevance to production-constrained gravity models. Environment and Planning 15(8): 1121-1132.

Gliebe J.P., Koppelman F.S. (2002) A model of joint activity participation between household members. Transportation 29(1): 49-72

Gordon-Larsen P., McMurray R.G., Popkin B.M. (2005) Determinants of adolescent physical activity and inactivity patterns. Pediatrics 105(6): E83. 
Gordon-Larsen P., Nelson M., Page P., Popkin B.M. (2006) Inequality in the built environment underlies health disparities in physical activity and obesity. Pediatrics 117(2): 417-424.

Gronau R. (1973) The allocation of time: the value of the housewife's time. American Economic Review 63(4): 635-651.

Habib K.M.N., Miller E.J. (2009) Modelling activity generation: a utility based model for activity-agenda formation. Transportmetrica 5(1): 3-23.

Handy S., Cao X., Mokhtarian P. (2005) Correlation or causality between the built environment and travel behavior? Evidence from northern California. Transportation Research Part D, 10(6): 427-444.

Kato H., Matsumoto M. (2009) Intra-household interaction in a nuclear family: a utilitymaximizing approach. Transportation Research Part B 43(2): 191-203.

Lockwood A., Srinivasan S., Bhat C.R. (2005) An exploratory analysis of weekend activity patterns in the San Francisco Bay area. Transportation Research Record 1926: 70-78.

Meloni I., Guala L., Loddo A. (2004) Time allocation to discretionary in-home, out-of-home activities and to trips. Transportation 31(1): 69-96.

Mitra R., Buliung R.N., Faulkner G.E.J. (2010) Spatial clustering and the temporal mobility of walking school trips in the Greater Toronto area, Canada. Health \& Place 16(4): 646-655.

MORPACE International, Inc. (2002) Bay Area Travel Survey Final Report, March.

Moudon A.V., Lee C., Cheadle A.D., Collier C.W., Johnson D.B., Schmid T.L., Weathers R.D. (2005) Cycling and the built environment, a U.S. perspective. Transportation Research Part D 10(3): 245-261.

Mowen A., Orsega-Smith E., Payne L., Ainsworth B., Godbey G. (2007) The role of park proximity and social support in shaping park visitation, physical activity, and perceived health among older adults. Journal of Physical Activity and Health 4(2): 167-179.

Nakai M. (2009) Socio-economic and age differences in women's cultural consumption: multidimensional preference analysis. In: Okada A., Imaizumi T., Bock H.-H., Gaul W. (eds) Cooperation in Classification and Data Analysis, Studies in Classification, Data Analysis, and Knowledge Organization, Springer-Verlag, Berlin, pp 179-188.

Papas M.A., Alberg A.J., Ewing R., Helzlsouer K.J., Gary T.L., Klassen A.C. (2007) The built environment and obesity. Epidemiologic Reviews 29(1): 129-143.

Pinjari A.R., Bhat C.R. (2010) A multiple discrete-continuous nested extreme value (MDCNEV) model: formulation and application to non-worker activity time-use and timing behavior on weekdays. Transportation Research Part B 44(4): 562-583.

Pinjari A.R., Bhat C.R., Hensher D.A. (2009) Residential self-selection effects in an activity time-use behavior model. Transportation Research Part B 43(7): 729-748.

Pinjari A.R., Eluru N., Bhat C.R., Pendyala R.M., Spissu E. (2008) Joint model of choice of residential neighborhood and bicycle ownership: accounting for self-selection and unobserved heterogeneity. Transportation Research Record 2082: 17-26. 
Pinjari A., Eluru N., Copperman R., Sener I.N., Guo J.Y., Srinivasan S., Bhat C.R. (2006) Activity-based travel-demand analysis for metropolitan areas in Texas: CEMDAP models, framework, software architecture and application results. Report 4080-8, prepared for the Texas Department of Transportation, Center for Transportation Research, The University of Texas at Austin, October 2006.

Reynolds K.D., Wolch J., Byrne J., Chou C.P., Feng G., Weaver S., Jerrett M. (2007) Trail characteristics as correlates of urban trail use. American Journal of Health Promotion 21(4S): 335-345.

Salmon J., Booth M.L., Phongsavan P., Murphy N., Timperio A. (2007). Promoting physical activity participation among children and adolescents. Epidemiologic Reviews 29(1): 144159.

Sener I.N., Bhat C.R. (2007) An analysis of the social context of children's weekend discretionary activity participation. Transportation 34(6): 697-721.

Sener I.N., Copperman R.B., Pendyala R.M., Bhat C.R. (2008) An analysis of children's leisure activity engagement: examining the day of week, location, physical activity level, and fixity dimensions. Transportation 35(5): 673-696.

Sener I.N., Eluru N., Bhat C.R. (2010) On jointly analyzing the physical activity participation levels of individuals in a family unit using a multivariate copula framework. Journal of Choice Modelling 3(3): 1-38.

Srinivasan S., Bhat C.R. (2006) A multiple discrete-continuous model for independent- and joint- discretionary-activity participation decisions. Transportation, 2006 TRB Special Issue, 33(5): 497-515.

Srinivasan S., Bhat C.R. (2008) An exploratory analysis of joint-activity participation characteristics using the American Time Use Survey. Transportation 35(3): 301-328.

Struber J. (2004) Considering physical inactivity in relation to obesity. The Internet Journal of Allied Health Sciences and Practice, 2(1).

Trolano R.P., Berrigan D., Dodd K., Masse L.C., Tilert T., McDowell M. (2008) Physical activity in the United States measures by accelerometer. Medicine \& Science in Sports \& Exercise 40(1): 181-188.

Trost S.G., Sallis J.F., Pate R.R., Freedson P.S., Taylor W.C., Dowda M. (2003) Evaluating a model of parental influence on youth physical activity. American Journal of Preventive Medicine 25(4): 277-282.

Tucker P., Gilliland J. (2007) The effect of season and weather on physical activity: a systematic review. Public Health 121(12): 909-922.

United States Department of Health and Human Services (USDHHS) (2008) 2008 Physical Activity Guidelines for Americans. Available at: http://www.health.gov/paguidelines/pdf/paguide.pdf

Westerterp K.R. (2003) Impact of vigorous and non-vigorous activity on daily energy expenditure. Proceedings of the Nutrition Society 62(3): 645-650. 
Table 1. Descriptive Statistics of Recreational Activity Participation

\begin{tabular}{|c|c|c|c|c|c|c|c|}
\hline \multirow{3}{*}{$\begin{array}{c}\text { Type of Recreational } \\
\text { Activity } \\
\text { (4448 adults in total } \\
\text { participating in } \\
\text { recreational activity) }\end{array}$} & \multirow{2}{*}{\multicolumn{2}{|c|}{$\begin{array}{l}\text { Total number (and } \\
\% \text { ) of individuals } \\
\text { participating }\end{array}$}} & \multirow{3}{*}{$\begin{array}{c}\text { Mean duration } \\
\text { of participation } \\
\text { among those } \\
\text { who participate } \\
\text { in the activity } \\
\text { (mins) }\end{array}$} & \multicolumn{4}{|c|}{$\begin{array}{c}\text { Number of individuals, and } \% \text { of total } \\
\text { number, who participate.... }\end{array}$} \\
\hline & & & & \multicolumn{2}{|c|}{$\begin{array}{l}\text { Only in activity } \\
\text { category }\end{array}$} & \multicolumn{2}{|c|}{$\begin{array}{l}\text { In the activity } \\
\text { category and other } \\
\text { activity categories }\end{array}$} \\
\hline & \# & $\%$ & & \# & $\%$ & \# & $\%$ \\
\hline In-home recreation (IHR) & 2266 & 50.9 & 221 & 1745 & 77.0 & 521 & 23.0 \\
\hline $\begin{array}{l}\text { Out-of-home physically } \\
\text { inactive recreation (PIR) }\end{array}$ & 1367 & 30.7 & 117 & 971 & 71.0 & 396 & 29.0 \\
\hline $\begin{array}{l}\text { Out-of-home physically } \\
\text { active recreation (PAR) }\end{array}$ & 1512 & 34.0 & 100 & 1075 & 71.1 & 437 & 28.9 \\
\hline \multicolumn{8}{|l|}{ Location } \\
\hline Club & 663 & 14.9 & 96 & 484 & 73.0 & 179 & 27.0 \\
\hline Neighborhood & 475 & 10.7 & 61 & 280 & 58.9 & 195 & 41.1 \\
\hline Outdoors & 411 & 9.2 & 142 & 285 & 69.3 & 126 & 30.7 \\
\hline \multicolumn{8}{|l|}{ Time-of-day } \\
\hline AM peak & 397 & 8.9 & 100 & 228 & 57.4 & 169 & 42.6 \\
\hline Midday & 561 & 12.6 & 101 & 373 & 66.5 & 188 & 33.5 \\
\hline PM peak & 387 & 8.7 & 90 & 262 & 67.7 & 125 & 32.3 \\
\hline Night & 256 & 5.8 & 78 & 165 & 64.5 & 91 & 35.5 \\
\hline
\end{tabular}


Table 2. Distribution of Participation in Physical Recreational Activities by Location and Time-of-day

\begin{tabular}{|c|c|c|c|c|c|c|c|c|c|c|}
\hline & & & \multicolumn{2}{|c|}{ AM peak } & \multicolumn{2}{|c|}{ Midday } & \multicolumn{2}{|c|}{ PM peak } & \multicolumn{2}{|c|}{ Night } \\
\hline & & & $\#$ & $\%$ & $\#$ & $\%$ & $\#$ & $\%$ & $\#$ & $\%$ \\
\hline & $\begin{array}{c}\text { \# of } \\
\text { individuals }\end{array}$ & $\%$ & 397 & $26.3^{*}$ & 561 & 37.1 & 387 & 25.6 & 256 & 16.9 \\
\hline \multirow{2}{*}{ Club } & \multirow{2}{*}{663} & \multirow{2}{*}{$43.8^{\dagger}$} & \multirow{2}{*}{134} & $20.2^{\ddagger}$ & \multirow{2}{*}{245} & 37.0 & \multirow{2}{*}{173} & 26.1 & \multirow{2}{*}{117} & 17.6 \\
\hline & & & & $33.8^{\varsigma}$ & & 43.7 & & 44.7 & & 45.7 \\
\hline \multirow{2}{*}{ Neighborhood } & \multirow{2}{*}{475} & \multirow{2}{*}{31.4} & \multirow{2}{*}{181} & 38.1 & \multirow{2}{*}{141} & 29.7 & \multirow{2}{*}{104} & 21.9 & \multirow{2}{*}{95} & 20.0 \\
\hline & & & & 45.6 & & 25.1 & & 26.9 & & 37.1 \\
\hline \multirow{2}{*}{ Outdoors } & \multirow{2}{*}{411} & \multirow{2}{*}{27.2} & \multirow{2}{*}{82} & 20.0 & \multirow{2}{*}{185} & 45.0 & \multirow{2}{*}{110} & 26.8 & \multirow{2}{*}{47} & 11.4 \\
\hline & & & & 20.7 & & 33.0 & & 28.4 & & 18.4 \\
\hline
\end{tabular}

${ }^{*}$ and ${ }^{\dagger}$ Percentages are based on the number of individuals who participate in at least one (out-of-home) physical recreational activity during the survey day; i.e., out of 1512 individuals.

${ }^{\ddagger}$ Percentages are based on total number of individuals participating in row activity type [(134/663) $\left.\times 100=20.2 \%\right]$.

${ }^{\varsigma}$ Percentages are based on total number of individuals participating in column activity type [(134/397) $\left.\times 100=33.8 \%\right]$. 
Table 3. The Mixed MDCEV Model Results: Baseline Parameter Estimates

\begin{tabular}{|c|c|c|c|c|c|c|c|c|c|c|c|c|c|c|c|c|c|c|}
\hline & \multicolumn{12}{|c|}{ Individual Demographics } & \multicolumn{6}{|c|}{ Work-Related Characteristics } \\
\hline & \multirow{2}{*}{\multicolumn{2}{|c|}{ Female }} & \multicolumn{4}{|c|}{ Age } & \multirow{2}{*}{\multicolumn{2}{|c|}{$\begin{array}{c}\text { Physically } \\
\text { disabled }\end{array}$}} & \multirow{2}{*}{\multicolumn{2}{|c|}{$\begin{array}{l}\text { Full time } \\
\text { student }\end{array}$}} & \multirow{2}{*}{\multicolumn{2}{|c|}{$\begin{array}{l}\text { Driver } \\
\text { license }\end{array}$}} & \multirow{2}{*}{\multicolumn{2}{|c|}{ Employed }} & \multicolumn{4}{|c|}{ Work-schedule flexibility } \\
\hline & & & \multicolumn{2}{|c|}{$\begin{array}{l}\text { Less than } \\
30 \text { years }\end{array}$} & \multicolumn{2}{|c|}{30 - 49 years } & & & & & & & & & \multicolumn{2}{|c|}{$\begin{array}{l}\text { Partially } \\
\text { flexible }\end{array}$} & \multicolumn{2}{|c|}{$\begin{array}{c}\text { Fully } \\
\text { flexible }\end{array}$} \\
\hline & Est. & t-stat & Est. & t-stat & Est. & t-stat & Est. & t-stat & Est. & t-stat & Est. & t-stat & Est. & t-stat & Est. & t-stat & Est. & t-stat \\
\hline In-home recreation (IHR) & -0.40 & -8.61 & - & - & - & - & - & - & - & - & - & - & - & - & - & - & - & - \\
\hline $\begin{array}{l}\text { Out-of-home physically } \\
\text { inactive recreation (PIR) }\end{array}$ & - & - & - & - & - & - & -0.47 & -2.44 & - & - & - & - & - & - & - & - & - & - \\
\hline \multirow{2}{*}{\multicolumn{19}{|c|}{$\begin{array}{l}\text { Out-of-home physically active } \\
\text { recreation (PAR) } \\
\text { Location }\end{array}$}} \\
\hline & & & & & & & & & & & & & & & & & & \\
\hline Club & -0.13 & -1.67 & - & - & - & - & - & - & - & - & - & - & 0.78 & 7.03 & 0.19 & 1.73 & 0.26 & 2.50 \\
\hline Neighborhood & -0.20 & -1.45 & -0.80 & -3.42 & - & - & - & - & - & - & -0.59 & -2.04 & - & - & - & - & - & - \\
\hline Outdoors & -0.52 & -5.63 & -0.29 & -1.94 & - & - & - & - & - & - & - & - & - & - & - & - & - & - \\
\hline \multicolumn{19}{|l|}{ Time-of-day } \\
\hline AM peak & 0.19 & 1.66 & - & - & - & - & -0.63 & -2.38 & -1.25 & -3.16 & - & - & -0.62 & -5.51 & - & - & - & - \\
\hline Midday & - & - & - & - & - & - & - & - & - & - & - & - & -0.90 & -7.84 & -0.53 & -3.35 & -0.23 & -1.65 \\
\hline PM peak & 0.14 & 1.31 & 0.94 & 6.18 & 0.61 & 5.21 & -0.63 & -2.38 & - & - & - & - & - & - & - & - & - & - \\
\hline Night & - & - & 0.72 & 5.07 & - & - & - & - & - & - & - & - & - & - & - & - & - & - \\
\hline \multicolumn{19}{|l|}{ Location / time-of-day } \\
\hline Club / PM peak & - & - & - & - & - & - & - & - & - & - & - & - & - & - & - & - & - & - \\
\hline Neighborhood / PM peak & - & - & - & - & -0.79 & -3.53 & - & - & - & - & - & - & - & - & - & - & - & - \\
\hline Outdoors / Midday & - & - & - & - & - & - & - & - & - & - & - & - & - & - & - & - & - & - \\
\hline
\end{tabular}


Table 3 (Continued.) The Mixed MDCEV Model Results: Baseline Parameter Estimates

\begin{tabular}{|c|c|c|c|c|c|c|c|c|c|c|c|c|c|c|}
\hline & \multicolumn{14}{|c|}{ Household Demographics } \\
\hline & \multirow{2}{*}{\multicolumn{2}{|c|}{$\begin{array}{l}\text { Nuclear } \\
\text { family }\end{array}$}} & \multicolumn{4}{|c|}{ Presence of kids } & \multicolumn{4}{|c|}{ Household Income } & \multirow{2}{*}{\multicolumn{2}{|c|}{$\begin{array}{l}\text { Number of } \\
\text { vehicles }\end{array}$}} & \multirow{2}{*}{\multicolumn{2}{|c|}{$\begin{array}{l}\text { Number of } \\
\text { bicycles }\end{array}$}} \\
\hline & & & \multicolumn{2}{|c|}{ Aged 0-4 } & \multicolumn{2}{|c|}{ Aged 5-15 } & \multicolumn{2}{|c|}{$\begin{array}{c}\text { Less than } \\
35 \mathrm{~K}\end{array}$} & \multicolumn{2}{|c|}{$\begin{array}{c}\text { Greater than } \\
90 \mathrm{~K}\end{array}$} & & & & \\
\hline & Est. & t-stat & Est. & t-stat & Est. & t-stat & Est. & t-stat & Est. & t-stat & Est. & t-stat & Est. & t-stat \\
\hline In-home recreation (IHR) & -0.20 & -3.29 & - & - & - & - & 0.28 & 4.46 & - & - & - & - & - & - \\
\hline $\begin{array}{l}\text { Out-of-home physically inactive } \\
\text { recreation (PIR) }\end{array}$ & - & & - & - & - & - & - & - & - & - & 0.04 & 1.36 & - & - \\
\hline \multirow{2}{*}{\multicolumn{15}{|c|}{$\begin{array}{l}\text { Out-of-home physically active } \\
\text { recreation (PAR) } \\
\text { Location }\end{array}$}} \\
\hline & & & & & & & & & & & & & & \\
\hline Club & - & - & - & - & - & - & - & - & 0.40 & 5.26 & - & - & - & - \\
\hline Neighborhood & - & - & - & - & - & - & - & - & - & - & - & - & 0.06 & 1.44 \\
\hline Outdoors & - & - & - & - & - & - & - & - & - & - & 0.12 & 2.52 & - & - \\
\hline \multicolumn{15}{|l|}{ Time-of-day } \\
\hline AM peak & - & - & - & - & -0.15 & -1.68 & - & - & - & - & - & - & - & - \\
\hline Midday & - & - & 0.35 & 2.41 & - & - & - & - & - & - & - & - & - & - \\
\hline PM peak & - & - & - & - & -0.15 & -1.68 & - & - & - & - & -0.32 & -4.24 & - & - \\
\hline Night & - & - & - & - & - & - & - & - & - & - & - & - & - & - \\
\hline \multicolumn{15}{|l|}{ Location / time-of-day } \\
\hline Club / PM peak & - & - & - & - & - & - & - & - & - & - & 0.21 & 2.04 & - & - \\
\hline Neighborhood / PM peak & - & - & - & - & - & - & - & - & - & - & - & - & - & - \\
\hline Outdoors / Midday & - & - & 0.34 & 1.50 & - & - & - & - & - & - & - & - & - & - \\
\hline
\end{tabular}


Table 3 (Continued.) The Mixed MDCEV Model Results: Baseline Parameter Estimates

\begin{tabular}{|c|c|c|c|c|c|c|c|c|c|c|c|c|}
\hline & \multicolumn{12}{|c|}{ Physical Environment Variables } \\
\hline & \multicolumn{4}{|c|}{ Seasonal Characteristics } & \multicolumn{4}{|c|}{$\begin{array}{c}\text { Transportation System Attributes/Built } \\
\text { Environment Characteristics }\end{array}$} & \multicolumn{4}{|c|}{ Zonal Demographics } \\
\hline & \multicolumn{2}{|c|}{ Winter } & \multicolumn{2}{|c|}{ Summer } & \multicolumn{2}{|c|}{$\begin{array}{l}\text { Accessibility to } \\
\text { physical } \\
\text { activity centers }\end{array}$} & \multicolumn{2}{|c|}{$\begin{array}{l}\text { 'Bikeway density’ } \\
\text { interacted with } \\
\text { 'number of } \\
\text { bicycles in the } \\
\text { household' }\end{array}$} & \multicolumn{2}{|c|}{$\begin{array}{l}\text { Fraction of } \\
\text { Caucasian } \\
\text { American } \\
\text { population }\end{array}$} & \multicolumn{2}{|c|}{$\begin{array}{l}\text { Mean household } \\
\text { income }\end{array}$} \\
\hline & Est. & t-stat & Est. & t-stat & Est. & t-stat & Est. & t-stat & Est. & t-stat & Est. & t-stat \\
\hline In-home recreation (IHR) & 0.17 & 2.15 & - & - & - & - & - & - & -0.29 & -2.54 & - & - \\
\hline $\begin{array}{l}\text { Out-of-home physically inactive } \\
\text { recreation (PIR) }\end{array}$ & - & - & - & - & - & - & - & - & - & - & - & - \\
\hline \multirow{2}{*}{\multicolumn{13}{|c|}{$\begin{array}{l}\text { Out-of-home physically active } \\
\text { recreation (PAR) } \\
\text { Location }\end{array}$}} \\
\hline & & & & & & & & & & & & \\
\hline Club & - & - & - & - & 3.96 & 5.27 & - & - & 0.60 & 2.96 & 0.004 & 2.30 \\
\hline Neighborhood & - & - & - & - & - & - & 0.04 & 4.12 & 0.35 & 1.14 & - & - \\
\hline Outdoors & - & - & 0.31 & 3.72 & - & - & - & - & 0.56 & 2.54 & - & - \\
\hline \multicolumn{13}{|l|}{ Time-of-day } \\
\hline AM peak & - & - & - & - & - & - & - & - & - & - & - & - \\
\hline Midday & - & - & - & - & - & - & - & - & - & - & - & - \\
\hline PM peak & - & - & - & - & - & - & - & - & - & - & - & - \\
\hline Night & - & - & - & - & - & - & - & - & - & - & - & - \\
\hline \multicolumn{13}{|l|}{ Location / time-of-day } \\
\hline Club / PM peak & - & - & - & - & - & - & - & - & - & - & - & - \\
\hline Neighborhood / PM peak & - & - & - & - & - & - & - & - & - & - & - & - \\
\hline Outdoors / Midday & - & - & - & - & - & - & - & - & - & - & - & - \\
\hline
\end{tabular}


Table 4. The Mixed MDCEV Model Results: Satiation Parameters

\begin{tabular}{|c|c|c|c|c|c|c|c|c|}
\hline & \multicolumn{4}{|c|}{ Individual Demographics } & \multicolumn{4}{|c|}{ Work-Related Characteristics } \\
\hline & \multicolumn{2}{|c|}{ Female } & \multicolumn{2}{|c|}{$\begin{array}{l}\text { Age } \\
\text { "Less than } \\
30 \text { years" }\end{array}$} & \multicolumn{2}{|c|}{ Employed } & \multicolumn{2}{|c|}{$\begin{array}{c}\text { Work Schedule } \\
\text { "Fully } \\
\text { Flexible" }\end{array}$} \\
\hline & Est. & t-stat & Est. & t-stat & Est. & t-stat & Est. & t-stat \\
\hline In-home recreation (IHR) & - & - & - & - & - & - & - & - \\
\hline $\begin{array}{l}\text { Out-of-home physically } \\
\text { inactive recreation (PIR) }\end{array}$ & 0.15 & 1.65 & - & - & -0.15 & -1.62 & -0.15 & -1.17 \\
\hline \multirow{2}{*}{\multicolumn{9}{|c|}{$\begin{array}{l}\text { Out-of-home physically } \\
\text { active recreation (PAR) } \\
\text { Location }\end{array}$}} \\
\hline & & & & & & & & \\
\hline Club & - & - & - & - & -0.13 & -1.23 & - & - \\
\hline Neighborhood & - & - & - & - & - & - & - & - \\
\hline Outdoors & 0.16 & 1.36 & - & - & - & - & - & - \\
\hline \multicolumn{9}{|l|}{ Time-of-day } \\
\hline AM peak & - & - & - & - & -0.12 & -1.04 & - & - \\
\hline Midday & - & - & - & - & - & - & - & - \\
\hline PM peak & -0.15 & -1.33 & - & - & - & - & - & - \\
\hline Night & - & - & -0.23 & -1.15 & - & - & - & - \\
\hline
\end{tabular}


Table 5. Impact of Changes in Demographic and Physical Environment Variables

\begin{tabular}{|c|c|c|c|c|c|c|c|c|c|c|c|c|c|c|c|c|c|c|c|c|}
\hline \multirow{5}{*}{$\begin{array}{l}\text { Alternatives } \\
\\
\text { Policy Scenarios }\end{array}$} & \multicolumn{20}{|c|}{ Activity Type } \\
\hline & \multirow{3}{*}{\multicolumn{2}{|c|}{$\begin{array}{l}\text { Non- } \\
\text { recreation } \\
\text { (NR) }\end{array}$}} & \multirow{3}{*}{\multicolumn{2}{|c|}{$\begin{array}{l}\text { In-home } \\
\text { Recreation } \\
\text { (IHR) }\end{array}$}} & \multirow{3}{*}{\multicolumn{2}{|c|}{\begin{tabular}{|c|} 
Out-of-home \\
Physically \\
Inactive \\
Recreation \\
(PIR)
\end{tabular}}} & \multicolumn{14}{|c|}{ Out-of-home Physically Active Recreation (PAR) } \\
\hline & & & & & & & \multicolumn{6}{|c|}{ Activity Location } & \multicolumn{8}{|c|}{ Activity Timing } \\
\hline & & & & & & & \multicolumn{2}{|c|}{ Club } & \multicolumn{2}{|c|}{ Neighborhood } & \multicolumn{2}{|c|}{ Outdoors } & \multicolumn{2}{|c|}{ AM Peak } & \multicolumn{2}{|c|}{ Midday } & \multicolumn{2}{|c|}{ PM Peak } & \multicolumn{2}{|c|}{ Night } \\
\hline & Mean & $\begin{array}{l}\text { Std. } \\
\text { Dev. }\end{array}$ & Mean & $\begin{array}{l}\text { Std. } \\
\text { Dev. }\end{array}$ & Mean & $\begin{array}{l}\text { Std. } \\
\text { Dev. }\end{array}$ & Mean & $\begin{array}{l}\text { Std. } \\
\text { Dev. }\end{array}$ & Mean & $\begin{array}{l}\text { Std. } \\
\text { Dev. }\end{array}$ & Mean & $\begin{array}{l}\text { Std. } \\
\text { Dev. }\end{array}$ & Mean & $\begin{array}{l}\text { Std. } \\
\text { Dev. }\end{array}$ & Mean & $\begin{array}{l}\text { Std. } \\
\text { Dev. }\end{array}$ & Mean & $\begin{array}{l}\text { Std. } \\
\text { Dev. }\end{array}$ & Mean & $\begin{array}{l}\text { Std. } \\
\text { Dev. }\end{array}$ \\
\hline $\begin{array}{l}\text { 'Age less than } 50 \text { years’ } \\
\text { (decreased by 25\%) }\end{array}$ & - & - & - & - & - & - & -14.76 & 4.32 & - & - & -17.65 & 7.96 & 0.24 & 0.14 & 1.66 & 0.96 & -24.13 & 7.94 & -10.17 & 3.26 \\
\hline $\begin{array}{l}\text { 'Presence of children } \\
\text { aged 0-15 years’ } \\
\text { (increased by } 25 \% \text { ) }\end{array}$ & - & - & - & - & - & - & -1.12 & 0.88 & -27.75 & 13.88 & -0.32 & 0.21 & -0.38 & 0.14 & 0.78 & 0.33 & -29.59 & 15.50 & - & - \\
\hline $\begin{array}{l}\text { ‘Vehicle ownership’ } \\
\text { (increased by 1) }\end{array}$ & - & - & - & - & 4.98 & 3.13 & -7.51 & 3.76 & -66.34 & 33.17 & 11.00 & 16.81 & 10.73 & 6.20 & 13.78 & 7.95 & -96.12 & 30.61 & 8.76 & 5.06 \\
\hline $\begin{array}{l}\text { 'Accessibility to physical } \\
\text { activity centers' } \\
\text { (increased by } 25 \% \text { ) }\end{array}$ & - & - & - & - & - & - & 45.48 & 2.13 & - & - & - & - & 12.75 & 7.36 & 9.29 & 5.36 & 9.83 & 5.68 & 13.61 & 7.86 \\
\hline $\begin{array}{l}\text { 'Bikeway density in the } \\
\text { zone interacted with the } \\
\text { number of bicycles in the } \\
\text { household' (increased by } \\
25 \% \text { ) }\end{array}$ & - & - & - & - & - & - & - & - & 74.81 & 7.98 & - & - & 21.12 & 12.20 & 13.99 & 8.08 & 10.90 & 6.29 & 28.80 & 16.63 \\
\hline $\begin{array}{l}\text { 'Fraction of Caucasian } \\
\text { American population’ } \\
\text { (decreased by } 25 \% \text { ) }\end{array}$ & - & - & 4.60 & 1.70 & - & - & -39.84 & 1.48 & -46.02 & 3.27 & -38.65 & 2.49 & -29.06 & 1.51 & -30.19 & 0.73 & -37.00 & 4.10 & -28.27 & 2.23 \\
\hline
\end{tabular}

